\title{
PROCEDIMENTO EXPERIMENTAL PARA A PROSPECÇÃO GEOQUÍMICA DE FLÚOR EM SOLOS
}

\author{
HELMUT BORN*
}

\begin{abstract}
An experimental method for the determination of cold-extractable fluoride in soils, for geochemical exploration purposes, is presented. Dilute perchloric acid and Na-citrate/K-nitrate buffer solutions were used and analysis performed by means of the fluoride specific electrode.

Several concentrations of acid and buffer solutions were tested on 6 artificial fluorite standards and 22 soil samples. Results indicate that the method can be helpful in the search of fluorite mineralizations in regions of thick soil cover.
\end{abstract}

INTRODUÇÃo O flúor é um dos elementos que freqüentemente está associado a mineralizações das mais diversas origens, constituindo-se num elemento-guia potencial para fins de prospecção geoquímica. A análise quantitativa de flúor, no entanto, até há pouco envolvia métodos titulométricos ou espectrométricos, após separação por distilação trabalhosa e lenta, não se prestando para fins de prospecção geoquímica. $\mathrm{O}$ aparecimento dos eletrodos específicos para íon-flúor** veio abrir novas perspectivas para sua determinação nos mais diversos materiais, tendo sido desenvolvidas várias técnicas atualmente de largo emprego; como exemplo dos mais conhecidos, temos a dosagem de flúor em águas em que a utilização de eletrodos específicos se tornou procedimento-padrão.

A dosagem geoquímica de flúor em águas, além de simples, pode ser efetuada diretamente no campo, apresenta bom rendimento e, sem dúvida, poderá vir a ter um amplo campo de aplicação no Brasil após trabalhos experimentais em regiões mineralizadas. Entre as técnicas analíticas, descritas na bibliografia especializada, desenvolvidas para a determinação de flúor em minerais e rochas, verifica-se que são aplicáveis para fosfatos facilmente solúveis ou envolvem métodos de solubilização pouco práticos para fins de prospecção geoquímica, que basicamente visa analisar grande número de amostras em curto espaço de tempo. Em diversas instituições pesquisou-se a aplicação da prospeç̧ão geoquímica (PG) para flúor contido em solos, utilizando-se, entre outros meios, simples ataque ácido a frio, como meio de solubilização. Entretanto, os resultados desses trabalhos só mais recentemente vieram a ser publicados (Pluger e Friedrich, 1972; Kesler et al, 1973; e Farrell, 1974).

Apesar de não se dispor, na época, de maiores detalhes sobre essas técnicas, foi iniciada, em 1972, uma série de ensaios experimentais visando estabelecer uma metodologiá que pudesse ser empregada no Brasil, onde a PG em solos apresenta grandes possibilidades de aplicação. Esses ensaios tiveram como finalidade principal verificar método de ataque, tipo de solução-tampão e procedimentos de medida adequados para fins de prospecção geoquímica para flúor em solos.

$\mathrm{Na}$ natureza, os minerais mais importantes, portadores de quantidades apreciáveis de flúor, são fluorita e flúor-apatita, além de outros menos abundantes ou de distribuição

* Departamento de Engenharia de Minas, Escola Politécnica da Universidade de São Paulo, C.P. 8174 , São Paulo, SP, Brasil

** Os eletrodos específicos detectam apenas o ín-fluoreto em soluçâa. Portanto, os ensaios apresentados a seguir dizem respeito exclusivamente a dosagens parciais do flúor contido em amostras 
muito particular. O flúor, no entanto, também se fixa posteriormente em minerais secundários, argilas e fosfatos sedimentares. Este estudo foi desenvolvido visando, principalmente, a possibilidade de deteç̧ão de concentrações anômalas de fluorita, em zonas onde constitui mineralização principal ou mineral de ganga.

Equipamento Na determinação do íon-flúor em solução, foram utilizados o eletrodo específico para fluoreto, Orion modelo 94-09 A e eletrodo de referência, Orion single junction modelo 90-01, acoplados a um milivoltímetro/pH-metro Metrohm, modelo E 5l2, utilizando-se sua escala ampliada $\pm 140 \mathrm{mV}$, graduada de $2 \mathrm{em} 2 \mathrm{mV}$.

As amostras foram dosadas em recipientes de plástico com $40 \mathrm{cc}$ de capacidade. Para efetuar as medidas, as soluções eram continuamente agitadas por meio de um agitador magnético.

Preparaçăo das amostras Para a determinação do procedimento analítico mais adequado e comparação dos resultados obtidos por diversos métodos, foram utilizados dois conjuntos de amostras:

a) 6 padrões artificiais, de granulação abaixo de 80 meshes, constituídos por misturas controladas de solo argiloso, praticamente isento de flúor, e fluorita, nas concentrações $0,1,0,2,0,5,1,2,5 \% \mathrm{CaF}_{2}$, equivalendo, respectivamente, a 487, 974, 2435, 4870, 9740 , 24350 ppmF.

b) 22 amostras naturais, com conteúdo extremamente variável de flúor, segundo análises preliminares. Estas amostras foram coletadas em região onde já era conhecida a ocorrência de fluorita em solos sobre depósito de tálus. A amostragem foi efetuada por meio de trado manual de $1 / 2$ pol de diâmetro, na profundidade de 20 a $90 \mathrm{~cm}$, com posterior secagem e trituração em cadinho de porcelana. $O$ material assim obtido, sem controle de granulação, constituiu uma série de amostras analisadas. Parte desse material foi então moído a -80 meshes, constituindo outra série de amostras.

Ensaios preliminares Estudos iniciais de solubilização foram feitos com quantidades variadas de ácido clorídrico e ácido perclórico, nas concentrações $0,2 \mathrm{~N}$ e 0,5 $\mathrm{N}$, sempre a frio. Esses ensaios foram efetuados com amostras de flúor-apatita pura e com os padrões artificiais, verificando-se maior solubilização por meio do ácido perclórico, que passou então a ser utilizado sistematicamente. Em todos os testes efetuados, o conteúdo de flúor das soluções foi determinado por comparação com curvas de calibração, construídas a partir de soluções-padrão contendo quantidades conhecidas de $\mathrm{NaF}$ e com as mesmas combinações de reagentes que estavam sendo testadas. Nesses ensaios estabeleceu-se também a quantidade de amostra a ser analisada em $0,5 \mathrm{~g}$, bem como o tempo de ataque em 2 horas. Já nesta fase verificou-se que a quantidade de fluorita solubilizada é muito pequena, mas que é possível identificar variações nas amostras.

Em seguida, foram efetuados ensaios de solubilização com $5 \mathrm{ml}$ de ácido perclórico, $0,2 \mathrm{~N}$ e $0,5 \mathrm{~N}$, atacando-se as amostras a frio, por período de 2 horas, com agitação das soluções de $30 \mathrm{em} 30 \mathrm{~min}$. Após o ataque, o volume da solução era elevado a $10 \mathrm{ml} \mathrm{com}$ $\mathrm{H}_{2} \mathrm{O}$ deionizada, seguida da adição de $10 \mathrm{ml}$ de solução-tampão, para manter o $\mathrm{pH}$ entre 5 e 7, de preferência entre 5,5 e 6,5, a firn de eliminar possíveis interferências e formação de complexos (ver Bibliografia).

As soluções-tampão testadas foram misturas de citrato de sódio/nitrato de $K$, nas concentrações $1 \mathrm{M}-0,2 \mathrm{M}$ e 0,2 M-0,2 M (Ingram, 1970). 
Utilizaçăo dos eletrodos Nas medidas efetuadas, as soluções apresentaram variações na concentração de $\mathrm{F}$ de várias centenas de vezes. Verificou-se que, no intervalo entre medidas sucessivas ou em períodos de repouso, o procedimento mais adequado com os eletrodos consiste em mergulhá-los em uma solução isenta de flúor, constituída apenas de água e solução-tampão.

Após efetuar uma série de medidas em soluções com alta concentração de flúor, caso se venham a efetuar leituras em soluções bem mais pobres, é necessário deixar os eletrodos mergulhados na solução de repouso por 10 ou 15 min. Desta maneira, os eletrodos passam. sempre de uma solução de baixa concentração para uma de concentração mais alta.

O tempo necessário para a estabilização da leitura do milivoltímetro, com este procedimento, é de $3 \mathrm{~min}$, após os quais pode ocorrer variação adicional de no máximo $2 \mathrm{mV}$, mas, em geral, da ordem de 0,5 a $1 \mathrm{mV}$. Como o reajuste do ponto de referência, após leituras de $\mathrm{pH}$ com o mesmo equipamento, pode ocasionar erros de $\pm 2 \mathrm{mV}$, este procedimento é suficiente nas condições mencionadas.

O procedimento acima descrito é necessário, pois as leituras obtidas em soluções de. baixa concentração de flúor, imediatamente depois de medidas efetuadas em soluções acentuadamente mais concentradas, mostraram ser totalmente falsas após período de 3 min, sendo necessários tempos de estabilização muito superiores, de 15 ou 30 min a várias horas.

Método de dosagem escolhido Ensaios preliminares com soluções de ácido perclórico $0,2 \mathrm{~N}$ e $0,5 \mathrm{~N}$ e soluções-tampão citrato de $\mathrm{Na} /$ nitrato de $\mathrm{K} 0,2 \mathrm{M}-0,2 \mathrm{M}$ e $1,0 \mathrm{M}-0,2 \mathrm{M}$ indicaram condições de $\mathrm{pH}$ no intervalo desejado, de 5,5 a 6,5, para as seguintes combinações:

$\begin{array}{cccc} & \text { Ácido perclórico } & \text { Sol.mtampão } & \text { pH solução } \\ 1) & 0,2 \mathrm{~N} & 0,2 \mathrm{M}-0,2 \mathrm{M} & 5,7 \\ \text { 2) } & 0,2 \mathrm{~N} & 1,0 \mathrm{M}-0,2 \mathrm{M} & 6,3 \\ 3) & 0,5 \mathrm{~N} & 1,0 \mathrm{M}-0,2 \mathrm{M} & 5,9\end{array}$

A dosagem de padrões artificiais, apesar das restrições relativas à sua preparação e homogeneização, indicou que as três combinações indicam de maneira clara a variação dos conteúdos de flúor (Fig. 1), embora a quantidade de fluorita solubilizada não seja proporcional ao conteúdo. Nas amostras mais pobres a solubilização é muito pequena (1-3\%), aumentando (até cerca de 10\%) nas amostras mais ricas.

No padrão 6 , contendo $5 \%$ de fluorita, verificou-se que uma das combinações (ácido perclórico $0,2 \mathrm{~N}$ e solução-tampão citrato de sódio $1 \mathrm{M}$-nitrato de potássio $0,2 \mathrm{M}$ ) apresenta resultados mais altos que as outras duas, principal motivo para sua escolha como procedimento mais adequado.

Dosagens repetidas de três padrões, com os dois procedimentos que apresentaram maiores resultados (ácido perclórico $0,2 \mathrm{~N}$ e $0,5 \mathrm{~N}$, com o mesmo tampão $1,0 \mathrm{M}-0,2 \mathrm{M}$ ), indicaram boa reprodutibilidade (Tab. I). Deve-se salientar, no entanto, que essas repetições foram efetuadas nas condiçoes mais favoráveis, isto é, medidas sucessivas de todas as soluções do mesmo padrão, do mais pobre ao mais rico. Pelo que já foi discutido anterior* mente, em especial quanto à estabilização das leituras, percebense que as discrepâncias provavelmente teriam sido maiores caso as medidas tivessem sido efetuadas em série (isto é, $\mathrm{P}_{2}, \mathrm{P}_{4}, \mathrm{P}_{6}$, depois outra série $\mathrm{P}_{2}, \mathrm{P}_{4}, \mathrm{P}_{6}$ etc.).

Aplicação do método em amostras naturais Após escolha do procedimento analítico mais favorável, foram realizados ensaios em 22 amostras naturais para verificar o efeito 


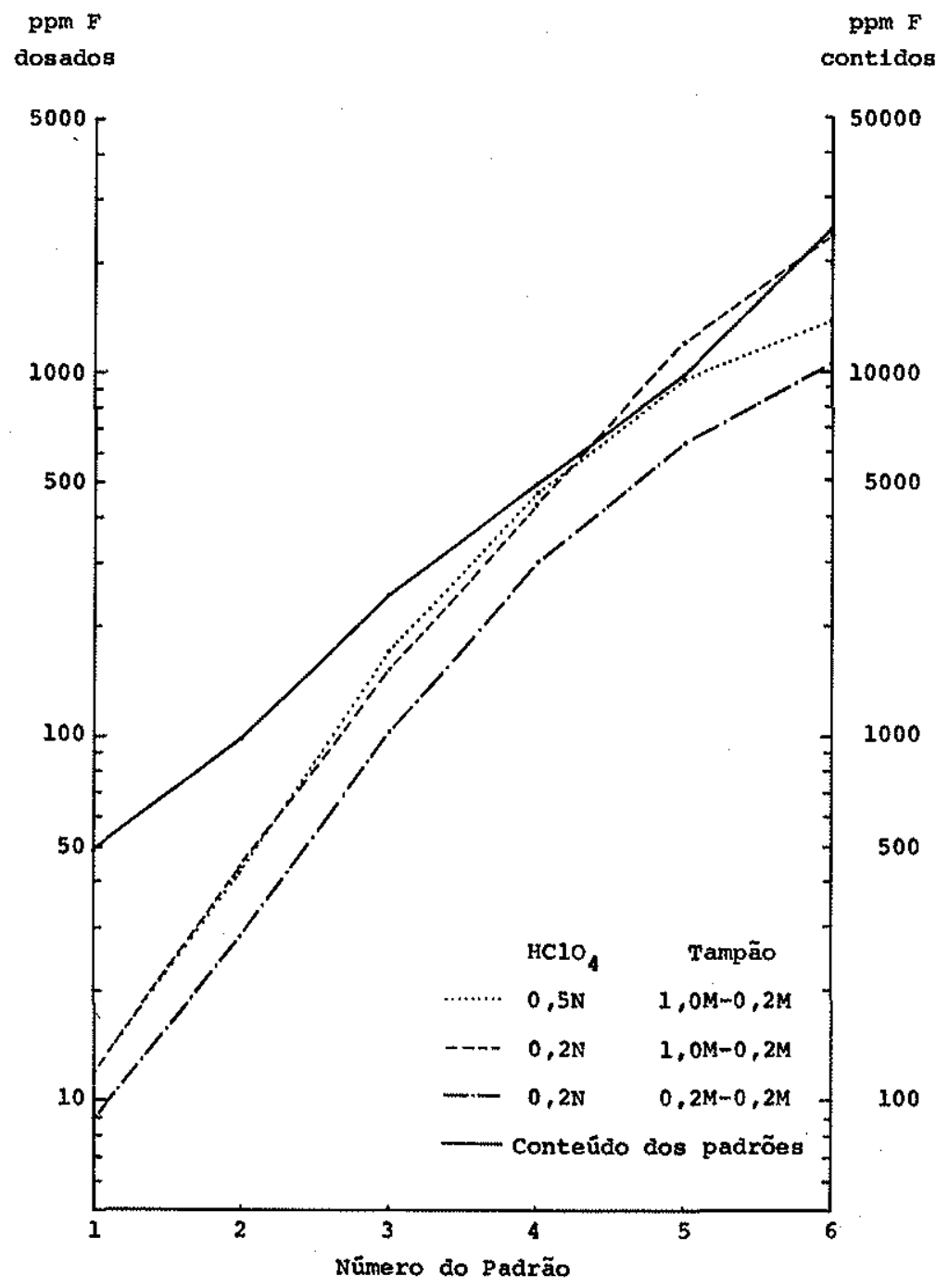

Figura 1 - Dosagens de flúor em padrões artificiais

Tabela I - Reprodutibilidade das dosagens para flúor em padróes artificiais

\begin{tabular}{c|ccc|ccc}
\hline $\begin{array}{c}\text { Método } \\
\text { de dosagem }\end{array}$ & $\begin{array}{c}\mathrm{HClO}_{4} \\
\text { Tampão }\end{array}$ & \multicolumn{2}{|c|}{$\begin{array}{c}0,2 \mathrm{~N} \\
1,0 \mathrm{M}-0,2 \mathrm{M}\end{array}$} & \multicolumn{2}{c}{$\begin{array}{c}\mathrm{HClO}_{4} \\
\text { Tampão }\end{array}$} & $\begin{array}{c}0,5 \mathrm{~N} \\
1,0 \mathrm{M}-0,2 \mathrm{M}\end{array}$ \\
\hline $\begin{array}{c}\text { Padrão } \\
\mathbf{n} .^{\circ}\end{array}$ & $\begin{array}{c}\text { Número de } \\
\text { dosagens }\end{array}$ & $\begin{array}{c}\text { Média } \\
\text { ppm F }\end{array}$ & $\begin{array}{l}\text { Intervalo } \\
\text { fiducial* }\end{array}$ & $\begin{array}{c}\text { Número de } \\
\text { dosagens }\end{array}$ & $\begin{array}{c}\text { Média } \\
\text { ppm F }\end{array}$ & $\begin{array}{c}\text { Intervalo } \\
\text { fiducial* }\end{array}$ \\
4 & 6 & 44 & $\pm 5,5$ & 5 & 42 & $\pm 5,3$ \\
6 & 6 & 428 & $\pm 9,6$ & 5 & 464 & $\pm 10,4$ \\
\hline
\end{tabular}

*Nivel de confiança $95 \%$ 
Tabela II - Resultados comparativos de dosagens para flúor em amostras de solo

\begin{tabular}{c|c|c|c|c}
\hline \multirow{2}{*}{ Amostra } & $\begin{array}{c}\text { Granulação } \\
\text { não-controlada }\end{array}$ & $\begin{array}{c}\text { Granulação } \\
-80 \#\end{array}$ & $\begin{array}{c}\text { Dosagem segundo } \\
\text { Ficklin }\end{array}$ & $\begin{array}{c}\text { F recalculado a } \\
\text { partir de } \mathrm{P}_{2} \mathrm{O}_{5}{ }^{*}\end{array}$ \\
\cline { 2 - 5 } & ppm F & ppm F & ppm F & ppm F \\
\hline \hline 1 & 0,1 & 0,1 & 184 & 180 \\
2 & 20 & 44 & 1560 & 1860 \\
3 & 800 & 1640 & 8800 & 2540 \\
4 & 400 & 540 & 2000 & 2310 \\
5 & 100 & 176 & 400 & 150 \\
6 & 280 & 460 & 2080 & 720 \\
7 & 340 & 600 & 3360 & 1780 \\
8 & 156 & 260 & 2000 & 1770 \\
9 & 540 & 1220 & 6280 & 1770 \\
10 & 460 & 920 & 2480 & 1500 \\
11 & 19 & 43 & 1360 & 265 \\
12 & 2 & 1760 & 1320 \\
13 & 54 & 66 & 1120 & 310 \\
14 & 10 & 10 & 584 & 930 \\
15 & 68 & 118 & 572 & 970 \\
16 & 540 & 760 & 1840 & 910 \\
17 & 460 & 820 & 3080 & 660 \\
18 & 280 & 460 & 2160 & 660 \\
19 & 112 & 142 & 800 & 180 \\
20 & 108 & 132 & 1220 & 180 \\
21 & 11 & 12 & 920 & 490 \\
22 & 10 & 20 & 372 & \\
\hline
\end{tabular}

${ }^{*}$ ppm $\mathrm{F}$ recalculadas a partir de dados de $\mathrm{P}_{2} \mathrm{O}_{5}$, admitindo-se flúor-apatita com $43 \% \mathrm{P}_{2} \mathrm{O}_{5}$ e $3,8 \% \mathrm{~F}$

da granulação nos resultados obtidos, além de uma comparação com o procedimento descrito por Ficklin (1970), envolvendo sinterização.

Os resultados das dosagens encontram-se na Tab. Il e Fig. 2. As amostras de granulação não-controlada indicaram quatro anomalias distintas com diversas intensidades.

Essas mesmas anomalias foram obtidas com o material moído abaixo de 80 meshes, por análise a frio, porém com intensidades mais pronunciadas.

Também a metodologia proposta por Ficklin indicou quatro anomalias, mas os resultados obtidos foram sempre muito mais elevados, devido ao próprio método de ataque. Deve-se salientar que a sinterização foi efetuada a $500^{\circ} \mathrm{C}$, pois no trabalho citado não há referência específica à temperatura considerada mais adequada. Ensaios posteriores indicaram que a temperatura de $600-650^{\circ} \mathrm{C}$ é a mais adequada. Os resultados aqui relatados, portanto, também não devem ser considerados correspondentes a flúor total.

As três curvas obtidas indicam, no entanto, que o procedimento mais simples e rápido, isto é, ataque a frio, em amostras de granulação não-controlada, apesar dos resultados mais baixos, permite identificar as mesmas anomalias indicadas pelas outras duas séries de dosagens.

A análise à lupa de solos e tálus da área de proveniência das amostras indicou, além da presença de fluorita, a existência de apatita. A fim de verificar se os resultados estariam indicando principalmente a presença de flúor-apatita, mais solúvel, efetuou-se a dosagem de $\mathrm{P}_{2} \mathrm{O}_{5}$ nas mesmas amostras, recalculando-se então a quantidade de $\mathrm{F}$ esperada, admi- 


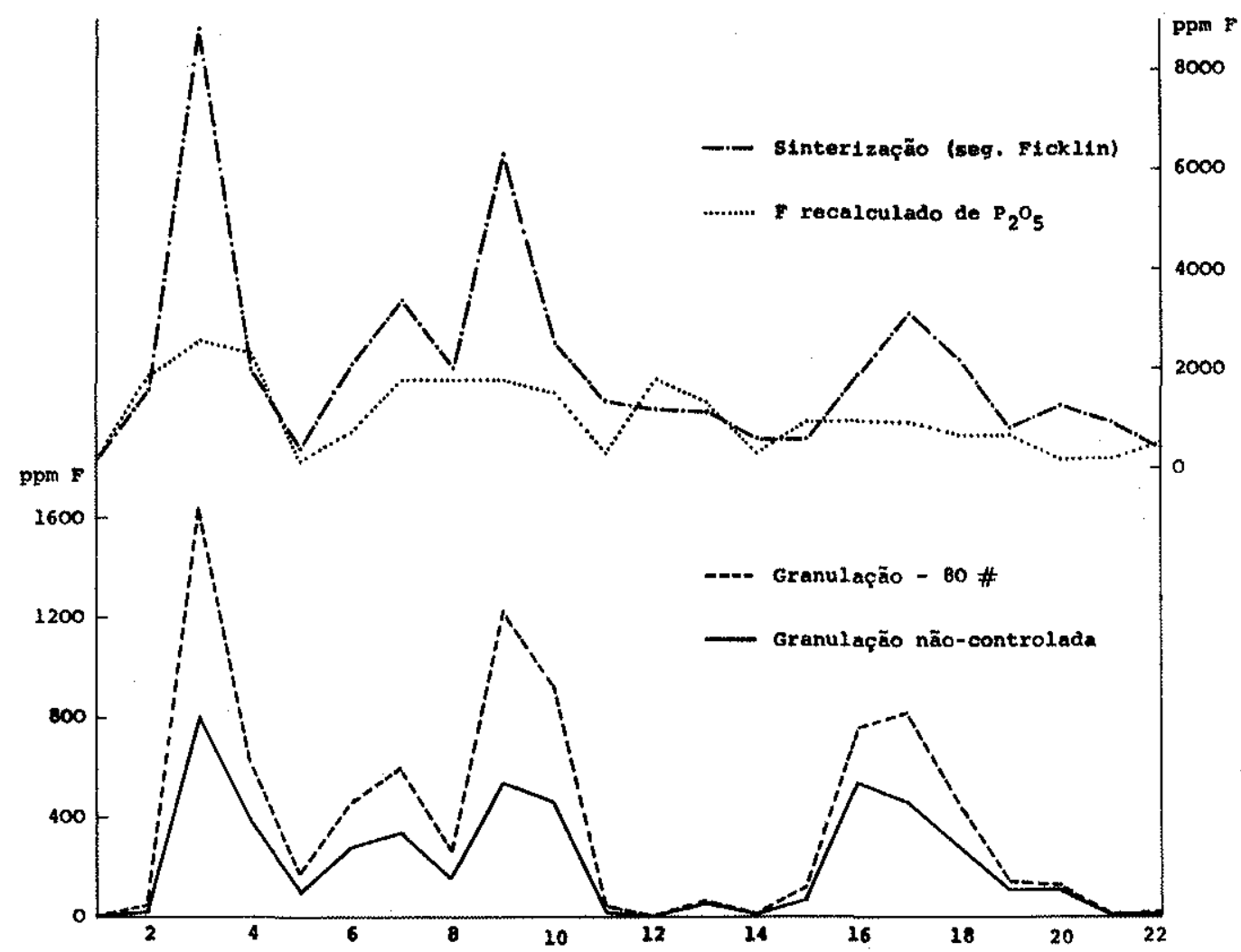

Figura 2 - Resultados de dosagens para flúor em 22 amostras de solo

tundo-se apatita com 3,8\% de F. Verifica-se que os valores assim calculados não coincidem nem são proporcionais às anomalias de flúor obtidas, apesar de uma certa concordância em vários pontos. Os valores obtidos pela técnica de Ficklin e a concordância das dosagens a frio com esses resultados indicam que a metodologia utilizada não é sensível apenas à parte mais solúvel do flúor.

Considerações finais Após os ensaios aqui discutidos, o método foi aplicado em numerosas amostras provenientes de diferentes localidades. Verificou-se que o procedimento, além de indicar concentrações anômalas de flúor relacionadas a mineralizações de fluorita, em algumas áreas permite obter indicações sobre a distribuição e os contatos entre diferentes litologias.

Embora a verificação do $\mathrm{pH}$ das soluções normalmente seja dispensável, por sua homogeneidade em torno de 6,3, há casos em que uma verificação se torna necessária. Em algumas amostras de solo observou-se efervescência quando do ataque ácido, apenas perceptível a bastante pronunciada. Nessas amostras o $\mathrm{pH}$ final da solução pode situar-se entre 7 e 9 , e os conteúdos de flúor verificados são anomalamente altos, caso não se efetue a correção do $\mathrm{pH}$. Em várias centenas de determinações, tal fato ocorreu esporadicamente em áreas de rochas carbonáticas. Em regiões de rochas calcárias recomenda-se, portanto, certa precaução enquanto não se verificar que o solo não contém fragmentos ou restos de minerais carbonáticos. 
Como o tempo de leitura de cada amostra é de $3 \mathrm{~min}$, o rendimento horário em geral está limitado a $12-15$ amostras, considerando-se a troca de recipientes e a lavagem dos eletrodos. Desta maneira, o rendimento diário de uma pessoa, só na parte analítica, pode ser calculado por volta de 80 amostras, incluído o tempo de ataque ácido e a preparação das soluçőes, após uma boa sistematização das operaçôes.

Este procedimento para dosagem parcial de F em solos, por extração a frio, constitui técnica diversa das discutidas por Farrell (1974). Os dois métodos de ataque a frio citados por esse autor, anteriormente descritos por Pluger e Friedrich (1972), devem fornecer resultados mais baixos, pois os reagentes utilizados na extração de $\mathrm{F}$ são bem mais diluídos, respectivamente, $\mathrm{NaOH} 0,001 \mathrm{~N}$ e $\mathrm{HCl} 0,02 \mathrm{~N}$. Já a solução $25 \% \mathrm{HClO}_{4}-75 \% \mathrm{HNO}_{3}$, diluída de cinco vezes, parece fornecer dados mais semelhantes à técnica aqui discutida, pois apresenta resultados da ordem de $10 \%$ do valor obtido pelo método de Ficklin modificado.

\section{BIBLIOGRAFIA}

EDMOND, G. R. - 1969 - Direct Determination of Fluoride in Phosphate Rock Samples Using the Specific Ion Electrode, Anal. Chem., 41 (10): $1327-1328$

EVANS, L., HOYLE, R.D. e MACASKILL, J. B. - 1970 - An Accurate and Rapid Method of Analysis for Fluorine in Phosphate Rocks, New Zealand Jl. Sci., 13 (1): 143-148

FARRLLL, B. L. - 1974 - Fluorine, a Direct Indicator of Fluorite Mineralization in Local and Regional Soil Geochemical Surveys, J. Geochem. Explor., 3: 227-244

FIGKLIN, W. H. - 1970 - A Rapid Method for the Determination of Fluoride in Rocks and Soils, Using an Ion-Selective Electrode, U.S. Geol. Survey Prof. Paper 700 C, pp. G 186-C 188

INGRAM, B. L. - 1970 - Determination of Fluoride in Silicate Rocks without Separation of Aluminum Using a Specific Ion Electrode, Anal. Chem., 42 (14): 1825-1827

KESLER, S. E., VAN LOON, J. C. e BATESON, J. H. - 1973 - Analysis of Fluoride in Rocks and an Application to Exploration, J. Geochem. Explor., 2: 11-17

ORION RESEARCH INC. - 1971 - Instruction Manual - Fluoride Electrode, Model 94-04

PLUGER, W. L. e FRIEDRICH, G. H. - 1972 - Determination of Total and Cold-Extractable Fluoride in Soils and Stream Sediments with an Ion Sensitive Fluoride Electrode, em M.J. Jones (editor), Geochemical Exploration 1972. Proc. 4th Int. Geochem. Explor. Symp., Institution of Mining and Mettalurgy, Londres, pp. 421-427 